\title{
ANULABILIDADE E O PARADOXO DO DOGMATISMO
}

\author{
Defeasibility and the dogmatism paradox
}

Resumo: O objetivo deste ensaio é examinar a recente crítica de Maria Lasonen-Aarnio à solução anulabilista do paradoxo do dogmatismo. Tal paradoxo consiste no argumento de que certos princípios epistêmicos autorizam qualquer sujeito cognoscente a desconsiderar contraevidências para o que ele sabe. Porém, esta atitude dogmática é comumente julgada como injustificada e o sujeito que a toma é comumente julgado como irracional. A solução anulabilista do paradoxo do dogmatismo foi posta em circulação por Gilbert Harman e sugere que o problema é resolvido assim que se abandona a suposição de que o conhecimento não pode ser derrotado por contraevidências. Lasonen-Aarnio acredita que tal solução é insatisfatória porque ainda haveria, em certas circunstâncias, justificação para ser dogmático mesmo admitindo e sofrendo derrota epistêmica. Desse modo, a solução anulabilista deixa ainda alguma medida de dogmatismo autorizada para o sujeito. Iniciaremos com uma introdução ao problema, explicando em que consiste o paradoxo do dogmatismo e expondo as diferentes versões nas quais foi apresentado. Em seguida, vamos nos voltar para uma versão do argumento pródogmatismo. Consideraremos, então, a solução anulabilista proposta por Harman e a crítica de Lasonen-Aarnio. Por fim, apresentaremos três objeções à eficácia da crítica de Lasonen-Aarnio.

Palavras-chave: Dogmatismo. Anulabilidade. Contraevidência. Gilbert Harman. Maria Lasonen-Aarnio.
Abstract: The aim of this essay is to examine Maria Lasonen-Aarnio's critique to the defeasibilist solution to the dogmatism paradox. The dogmatism paradox's argument is that some principles on knowledge entitle any knower to disregard counterevidences against what she knows. However, this dogmatic attitude is usually seen as unjustified and the dogmatist is usually seen as irrational. The defeasibilist solution to the dogmatism paradox was put forward by Gilbert Harman. It suggests that the problem is solved if we abandon the idea that knowledge cannot be defeated. Lasonen-Aarnio holds that the defeasibilist solution is not satisfactory, since there are still some cases where knowledge suffers defeat and the knower is entitled to disregard the defeater nonetheless. We will begin with an introduction to the puzzle, by presenting some versions of it. We will assess a specific pro-dogmatism argument. Then, we will present the defeasiblist solution and examine Lasonen-Aarnio's critique. Finally, we will put forward three new objections to Lasonen-Aarnio's critique.

Keywords: Dogmatism. Defeasibility. Counterevidence. Gilbert Harman. Maria Lasonen-Aarnio.

\footnotetext{
* Doutorando pelo Programa de Pós-graduação em Filosofia da Pontifícia Universidade Católica do Rio Grande do Sul, Bolsista CAPES/PROEX. Contato: jrfett01@gmail.com
}

\begin{tabular}{|c|c|l|l|c|c|}
\hline Intuitio & $\begin{array}{c}\text { ISSN } \\
1983-4012\end{array}$ & Porto Alegre & Vol.9- N $^{\circ} .2$ & $\begin{array}{c}\text { Dezembro } \\
2016\end{array}$ & pp. 133-149 \\
\hline
\end{tabular}




\section{Introdução}

Algumas vezes, quando você sabe que certa proposição é verdadeira, pode parecer razoável a você desconsiderar evidências que os outros lhe oferecem contra essa proposição. Por exemplo, se você sabe que o homem foi à lua em 1969 (com base nas inúmeras evidências e testemunhos em favor da verdade disto), então ainda que o seu vizinho lhe diga que isto é falso e não passa de uma grande armação do governo americano, você está autorizado a desconsiderar o testemunho dele. Talvez você pense que o seu vizinho está querendo lhe pregar uma peça, ou ainda que ele esteja impressionado pelas teorias da conspiração que assistiu no YouTube.

No entanto, no mais das vezes, desconsiderar evidências contra o que você sabe não parece uma atitude razoável da sua parte. Pelo contrário, ao não considerar alguma contraevidência que alguém lhe oferece, você está sendo dogmático, e esta postura é vista como um péssimo modo de manutenção de crenças. Ao ser atacado por contraevidência, o status epistêmico da sua crença-alvo é desafiado e parece ser neutralizado até que você o restaure.

Contra a intuitiva ideia de que o dogmatismo nunca é uma atitude racional, foi apresentado à comunidade filosófica um argumento que supostamente prova que se você sabe que P, então você está autorizado a ser dogmático quanto a se P. A ideia de que a tomada de uma atitude dogmática pode ser justificada para quem possui conhecimento ficou conhecida na literatura como o paradoxo do dogmatismo.

O raciocínio que supostamente autoriza o dogmatismo para qualquer sujeito que possui conhecimento é expresso por Gilbert Harman no seguinte excerto:

Se eu sei que P é verdadeiro, eu sei que qualquer evidência contra P é evidência contra algo que é verdadeiro; então eu sei que tal evidência é enganadora. Mas eu deveria desconsiderar evidência que eu sei que é enganadora. Então, uma vez que eu sei que P é verdadeiro, eu estou em posição de desconsiderar qualquer futura evidência que pareça ir contra $\mathrm{P}^{1}$.

Roy Sorensen ajudou-nos a ilustrar o problema ao considerar a seguinte instanciação do raciocínio empregado pelo dogmatista. Imagine que eu acabo de deixar meu carro no estacionamento e, ao chegar ao escritório, encontro o meu confiável e distinto colega que, então, me diz que o meu carro não está lá. Após ouvi-lo, eu penso o seguinte:

(1) Meu carro está no estacionamento.

\footnotetext{
1 "If I know that $\mathrm{h}$ is true, I know that any evidence against $\mathrm{h}$ is evidence against something that is true; so I know that such evidence is misleading. But I should disregard evidence that I know is misleading. So, once I know that $\mathrm{h}$ is true, I am in a position to disregard any future evidence that seems to tell against h.”. HARMAN, G. Thought. Princeton University Press, 1973, p. 148.
}

\begin{tabular}{|c|c|l|l|c|c|}
\hline Intuitio & $\begin{array}{c}\text { ISSN } \\
1983-4012\end{array}$ & Porto Alegre & Vol.9- No.2 & $\begin{array}{c}\text { Dezembro } \\
2016\end{array}$ & pp. 133-149 \\
\hline
\end{tabular}


(2) Se o meu carro está no estacionamento e meu colega me diz o contrário, então o testemunho do meu colega é enganador.

(3) Se o meu colega me diz que o meu carro não está no estacionamento, então o testemunho dele é enganador.

(4) O meu colega me diz que o meu carro não está no estacionamento.

(5) [Portanto], o testemunho do meu colega é enganador².

Eu sei que o conteúdo de (1) é verdadeiro - vamos assumir isso; eu sei que o meu carro está no estacionamento. Eu também sei que o conteúdo de (2) é verdadeiro; um item de conhecimento a priori. É analiticamente verdadeiro que se P é o caso, então qualquer contraevidência para P é enganadora - isto é, evidência contra algo verdadeiro. A premissa (3) é equivalente à premissa (2), portanto eu também posso saber que ela é verdadeira. Assim, quando eu ouço que o meu colega me diz que o meu carro não está no estacionamento, eu ganho justificação para crer (5), que o testemunho dele é enganador, por modus ponens de (3) e (4).

Costuma-se, na literatura, resumir o paradoxo no desconcertante slogan "Conhecimento gera dogmatismo”, pois sempre que eu sei que uma proposição é verdadeira, se eu emprego um raciocínio assemelhado ao raciocínio acima, eu sou racional ao tomar qualquer contraevidência para a minha crença nessa proposição como evidência enganadora.

Um outro modo de pensar o paradoxo do dogmatismo é ver como qualquer sujeito cognoscente que possui conhecimento pode ficar imune ao ataque de contraevidências antes mesmo de as encontrar. Esta é, na realidade, a ideia original do paradoxo, tal como foi apresentado pela primeira vez por Saul Kripke, em uma palestra em 1972. Vejamos como Kripke formula o paradoxo que ele descobriu:

1. S sabe que P. [Suposição]

2. Se P é verdadeiro, então qualquer evidência contra P é enganadora. [Suposição]

3. S sabe que 2 é o caso. [Suposição]

4. S sabe que qualquer evidência contra $\mathrm{P}$ é enganadora (isto é, leva a uma conclusão falsa). [de 1,2,3, via Fecho-conhecimento]

5. Se S sabe que tomar uma ação T leva a uma consequência C, e $S$ deseja, acima de tudo, evitar C, então S deveria decidir não tomar uma ação do tipo T. [Suposição]

6. Se $\mathrm{S}$ sabe que aceitar qualquer evidência contra $\mathrm{P}$ tem como consequência uma crença falsa, e $\mathrm{S}$ deseja, acima de tudo, evitar adquirir uma crença falsa, então $\mathrm{S}$ deveria decidir agora não aceitar qualquer evidência contra P. [Instanciação de 5]

7. S sabe que qualquer evidência contra P tem como consequência uma crença falsa. [via 4]

${ }^{2}$ Cf. SORENSEN, R. Dogmatism, junk knowledge, and conditionals. Philosophical Quarterly 38 (153), 1988 , p.438.

\begin{tabular}{|c|c|c|c|c|c|}
\hline Intuitio & $\begin{array}{c}\text { ISSN } \\
1983-4012\end{array}$ & Porto Alegre & Vol.9- No.2 & $\begin{array}{c}\text { Dezembro } \\
2016\end{array}$ & pp. 133-149 \\
\hline
\end{tabular}


8. S deveria decidir agora não aceitar qualquer evidência contra P. [de 6 e 7, via modus ponens $]^{3}$.

Embora a ideia nuclear seja a mesma nas diferentes versões do paradoxo do dogmatismo recém apresentadas - a ideia de que o conhecimento nos compromete, em algum sentido, com uma atitude dogmática - há uma diferença importante entre elas a ser marcada, proposta recentemente por Rodrigo Borges ${ }^{4}$. Ele procurou persuadir-nos de que há duas formas de dogmatismo que não devem ser confundidas, pois críticas e respostas para uma das versões podem não se aplicar à outra das versões. Ele sugere que há o problema do dogmatismo sincrônico e o problema do dogmatismo diacrônico.

A versão sincrônica do dogmatismo tem a ver com a atitude que $S$ deve tomar agora em relação ao que ele deve fazer ao ser confrontado com contraevidência para o que ele sabe. A versão diacrônica do dogmatismo, por sua vez, tem a ver com a atitude que $\mathrm{S}$ deveria tomar no futuro, quando (e se) essa contraevidência de fato aparecesse. Sendo assim, de acordo com a distinção de Borges, a forma do argumento paradoxal nas versões de Harman e Sorensen (que apresentamos anteriormente) é a forma diacrônica, enquanto que a forma do argumento paradoxal na versão de Kripke é a forma sincrônica ${ }^{5}$. Nosso interesse aqui será na versão diacrônica do paradoxo, isto é, a versão do paradoxo que tem a ver com a atitude que o sujeito pode ou deve tomar no momento em que ele é confrontado com contraevidência para o que ele sabe. No que segue, apresentaremos a versão do argumento para o dogmatismo diacrônico, que será o objeto deste ensaio.

\section{O argumento pró-dogmatismo}

Maria Lasonen-Aarnio, na intenção de reconstituir a ideia de Harman em um argumento válido, sugeriu que a versão diacrônica do argumento pró-dogmatismo pode ser expressa do seguinte modo:

(1) Para qualquer proposição h e tempos t e to, se t é anterior ao tempo to, e $S$ sabe que $h$ em $t$, e nos tempos até e incluindo $\mathrm{t}_{0} \mathrm{~S}$ continua a crer em $\mathrm{h}$ sobre a mesma base como em $t$, então em $t_{0} S$ sabe que $h$.

(2) Para qualquer proposição $h$, tempo t, e evidência $E$, se em t $S$ sabe que h é verdadeiro e em t S sabe que E é evidência contra h, então em t S está em posição de saber que E é evidência enganadora contra $h$.

(3) Para qualquer proposição h, tempo t, e evidência E, se em t S está em posição de saber que $E$ é evidência enganadora contra h, então em $t \mathrm{~S}$ está em posição de desconsiderar justificadamente $\mathrm{E}$ enquanto $\mathrm{E}$ incide sobre $\mathrm{h}$.

Portanto,

${ }^{3}$ Cf. KRIPKE, S. Philosophical Troubles. Collected Papers Vol I. Oxford University Press, 2011, p. 43-44, e Cf. BORGES, R. On synchronic dogmatism. Synthese 191 (11), 2015, 3677-3693, p. 3681.

${ }^{4}$ Veja BORGES, R. On synchronic dogmatism. Synthese 191 (11), 2015, 3677-3693.

${ }^{5} \mathrm{O}$ argumento de Kripke é criticado na literatura por BORGES, 2015.

\begin{tabular}{|c|c|l|l|c|c|}
\hline Intuitio & $\begin{array}{c}\text { ISSN } \\
1983-4012\end{array}$ & Porto Alegre & Vol.9- N $^{\circ} .2$ & $\begin{array}{c}\text { Dezembro } \\
2016\end{array}$ & pp. 133-149 \\
\hline
\end{tabular}


(4) Para qualquer proposição $h$, tempos $t$ e $t_{0}$, e evidência $E$, se t é anterior ao tempo $t_{0}$, e $\mathrm{S}$ sabe que $\mathrm{h}$ em $\mathrm{t}$, e nos tempos até e incluindo $\mathrm{t}_{0} \mathrm{~S}$ continua a crer em $\mathrm{h}$ sobre a mesma base como em $t$, e em $t_{0} \mathrm{~S}$ sabe que $\mathrm{E}$ é evidência contra $\mathrm{h}$, então em $\mathrm{t}_{0} \mathrm{~S}$ está em posição de desconsiderar justificadamente $\mathrm{E}$ enquanto $\mathrm{E}$ incide sobre $\mathrm{h}^{6}$.

Uma vez que não queremos aceitar a conclusão, devemos examinar as premissas do argumento, entender com o que cada uma delas nos compromete e, assim, decidir o que deve ser abandonado.

A premissa (1) assume o assim-chamado princípio da estabilidade do conhecimento (ou princípio da não-anulabilidade do conhecimento). Tal princípio diz o seguinte:

"Se S sabe que P em t, então nenhuma nova evidência derrotará o conhecimento de P para S”7.

A premissa (2) expõe a justificação de S para a seguinte inferência, quando S sabe que P: (i) P, (ii) Se $P$, então evidência contra $P$ é enganadora, (iii) $E$ é evidência contra $P$, portanto (iv) $E$ é evidência enganadora. Se assumimos que evidência enganadora quer dizer algo como evidência para descrer ou suspender o juízo quanto a uma proposição verdadeira, então vemos que a inferência acima é válida.

A premissa (3) é uma instanciação do assim-chamado princípio da intitulação. Tal princípio diz o seguinte:

"Se S sabe que E é evidência enganadora contra P, então S está justificado em desconsiderar E”.

Finalmente, a premissa (4) é a conclusão dogmatista. Se S sabe que P, e se ele é confrontado com evidência enganadora contra $\mathrm{P}$, e faz a devida inferência expressa pela premissa (2), então o dogmatismo passa a ser uma atitude racional para S.

Antes de examinarmos a solução anulabilista do paradoxo, é importante ganharmos mais clareza sobre o que a premissa (3) intitula o sujeito a fazer, a saber, desconsiderar evidência. Lasonen-Aarnio crê que as explicações mais plausíveis para o que significa desconsiderar evidência são os seguintes (onde ' $E$ ' está para ‘evidência enganadora contra P’):

A. S não abandona a sua crença em P em vista de E.

B. S não baixa o seu grau de crença em $\mathrm{P}$ em vista de $\mathrm{E}^{9}$.

6 “(1) For any proposition $\mathrm{h}$ and times $\mathrm{t}$ and t0, if $\mathrm{t}$ is earlier than t0, at $\mathrm{t} \mathrm{S}$ knows $\mathrm{h}$, and at times up to and including t0 $\mathrm{S}$ continues to believe $\mathrm{h}$ on the same basis as at $t$, then at t0 $\mathrm{S}$ knows $\mathrm{h}$. (2) For any proposition $\mathrm{h}$, time $t$ and evidence $\mathrm{E}$, if at $\mathrm{t} S$ knows that $\mathrm{h}$ is true and at $\mathrm{S}$ knows that $\mathrm{E}$ is evidence against $\mathrm{h}$, then at $\mathrm{t} S$ is in a position to know that $\mathrm{E}$ is misleading evidence against $\mathrm{h}$. (3) For any proposition $\mathrm{h}$, time $\mathrm{t}$ and evidence $\mathrm{E}$, if at $\mathrm{t} S$ is in a position to know that $\mathrm{E}$ is misleading evidence against $\mathrm{h}$, then at $\mathrm{t} S$ is in a position to justifiably disregard $\mathrm{E}$ as it bears on $\mathrm{h}$. Therefore, (4) For any proposition $\mathrm{h}$, times $\mathrm{t}$ and $\mathrm{t} 0$ and evidence $\mathrm{E}$, if $\mathrm{t}$ is earlier than $\mathrm{t} 0$, at $\mathrm{t} \mathrm{S}$ knows $\mathrm{h}$, at times up to and including t0 $\mathrm{S}$ continues to believe $\mathrm{h}$ on the same basis as at $\mathrm{t}$, and at t0 $\mathrm{S}$ knows that $\mathrm{E}$ is evidence against $\mathrm{h}$, then at $\mathrm{t} 0 \mathrm{~S}$ is in a position to justifiably disregard $\mathrm{E}$ as it bears on h.” LASONEN-AARNIO, M. The dogmatism puzzle. Australasian Journal of Philosophy 94 (3), 2014, 417-432, p. 420.

7 Este princípio foi originalmente proposto por HINTIKKA, 1962, e serviu como inspiração para as teorias anulabilistas do conhecimento propostas como soluções ao problema de Gettier. Veja LEHRER, K. Knowledge, Truth and Evidence. Analysis 25 (5), 1965, 168-175.

${ }^{8}$ Cf. LASONEN-AARNIO, M. The dogmatism puzzle. Australasian Journal of Philosophy 94 (3), 2014, p. 419.

${ }^{9}$ Cf. LASONEN-AARNIO, M. The dogmatism puzzle. Australasian Journal of Philosophy 94 (3), 2014, p. 422.

\begin{tabular}{|c|c|l|l|c|c|}
\hline Intuitio & $\begin{array}{c}\text { ISSN } \\
1983-4012\end{array}$ & Porto Alegre & Vol.9- N $^{\circ} .2$ & $\begin{array}{c}\text { Dezembro } \\
2016\end{array}$ & pp. 133-149 \\
\hline
\end{tabular}


Há uma mesma ideia central compartilhada pelas duas explicações oferecidas acima. LasonenAarnio explica o ponto:

A ideia geral é que desconsiderar evidência que incide sobre h será uma questão de deixar de ajustar os seus estados de crença em h em resposta à evidência. Poderia ser deixar de ajustar a sua crença tudo-ou-nada em h por continuar crendo em h, deixar de ajustar o seu grau de crença em h, ou ambos ${ }^{10}$.

Antes, porém, de investigarmos qual (se alguma) das explicações é superior, é importante levarmos em conta que há dois modelos doxásticos para o estado de crença. Há o modelo tradicional qualitativo, da crença “tudo ou nada”, cujas atitudes doxásticas possíveis são somente três, a saber, crença, descrença, e suspenção de juízo. Há também o modelo gradual, de graus de crença, cujas atitudes doxásticas podem variar dentro de um espectro de probabilidades subjetivas dada a evidência do sujeito, ou podem variar em graus de confiança na verdade de proposições.

Lasonen-Aarnio crê que a opção A - não abandonar a crença em $\mathrm{P}$ em vista de $\mathrm{E}$ - não é a melhor opção para se entender o que significa desconsiderar evidência, uma vez que é importante acomodar estados de crença graduais, se eles existem. A opção B - não baixar o grau de crença em P em vista de E é a única que torna isso possível. Note, além disso, que a opção B acomoda uma outra possibilidade, a saber, a possibilidade de baixar o grau de crença em P em vista de E, mas não abandonar P. Nem sempre baixar o grau de crença em P implicará abandonar a crença em P; porém, se o sujeito o fizesse, parece que ele estaria considerando a evidência contra P.

Sob esta leitura, tomando a opção B como a melhor explicação para a atitude de desconsiderar evidência, o princípio de intitulação ficaria como o seguinte:

“Se um sujeito sabe que E é evidência enganadora contra h, então ele está justificado a não baixar o seu grau de crença em h à luz de $\mathrm{E}^{\prime 11}$.

Compreendendo quais os princípios e suposições subjacentes ao argumento pró-dogmatismo e entendendo no que consiste desconsiderar evidência, vamos, no que segue, examinar a solução anulabilista do paradoxo.

\section{A Solução Anulabilista}

Na mesma ocasião em que apresentou o paradoxo pela primeira vez na literatura, Harman ofereceu a sua própria solução ao problema. De acordo com ele, o paradoxo depende de um princípio

10 “The general idea is that disregarding a piece of evidence as it bears on $\mathrm{h}$ will be a matter of failing to adjust one's belief states in $\mathrm{h}$ in response to the evidence. It might be failing to adjust one's all-out belief in $\mathrm{h}$ by continuing to believe $h$, failing to adjust one's credence in $h$, or both LASONEN-AARNIO, M. The dogmatism puzzle. Australasian Journal of Philosophy 94 (3), 2014, 417-432, p. 423.

${ }^{11}$ LASONEN-AARNIO, M. The dogmatism puzzle. Australasian Journal of Philosophy 94 (3), 2014, p. 424.

\begin{tabular}{|c|c|l|l|c|c|}
\hline Intuitio & $\begin{array}{c}\text { ISSN } \\
1983-4012\end{array}$ & Porto Alegre & Vol.9- N $^{\circ} .2$ & $\begin{array}{c}\text { Dezembro } \\
2016\end{array}$ & pp. 133-149 \\
\hline
\end{tabular}


epistêmico que se mostra falso sob investigação, a saber, o princípio da estabilidade do conhecimento (ou princípio da não-anulabilidade do conhecimento), encapsulado pela premissa (1) do argumento pródogmatismo de Lasonen-Aarnio que recém consideramos.

Harman pede que prestemos atenção ao fato de que mudanças no status epistêmico das nossas crenças acontecem sempre que adquirimos novas evidências. Novas evidências que você recebe e considera terão potenciais implicações em relação às demais crenças que você mantém, tais como o ajuste ou revisão de uma parte ou de todo o seu sistema doxástico. Lembremo-nos novamente do exemplo de Sorensen. Notemos que, naquela circunstância, ao ganhar contraevidência, não é possível desconsiderá-la porque ela neutraliza as premissas do próprio raciocínio que nos autorizaria a desconsiderá-la.

A ideia central da solução que Harman sugeriu para o paradoxo é que contraevidência muda o que eu sei. Para ilustrar melhor esta ideia, considere novamente o caso que Sorensen apresentou:

(1) Meu carro está no estacionamento.

(2) Se o meu carro está no estacionamento e meu colega me diz o contrário, então o testemunho do meu colega é enganador.

(3) Se o meu colega me diz que o meu carro não está no estacionamento, então o testemunho dele é enganador.

(4) O meu colega me diz que o meu carro não está no estacionamento.

(5) [Portanto], o testemunho do meu colega é enganador ${ }^{12}$.

Mesmo que eu saiba todas as premissas de (1) até (5), quando o meu colega me diz que o meu carro não está no estacionamento, eu não posso crer que o testemunho dele é enganador, porque assim que ele me oferece o seu testemunho - isto é, assim que ele profere que o meu carro não está no estacionamento - eu perco a minha justificação para crer (1), que o meu carro está no estacionamento, e não tenho mais justificação para fazer a inferência que me levaria até (5); afinal, a premissa (1) era indispensável naquela inferência.

Desse modo, a sugestão de Harman é que eu não tenho intitulação para crer (5) por modus ponens porque quando (4) entra no meu sistema de crenças, ela, a premissa (4), cancela a minha justificação para as premissas daquele modus ponens.

A resposta de Harman é chamada de solução anulabilista porque Harman se livra do compromisso com a atitude dogmática mostrando a falsidade do princípio da estabilidade do conhecimento. Ele mostra que é implausível defender que um sujeito $S$ tem conhecimento de uma proposição somente se ele permaneceria tendo conhecimento dela independente de qualquer nova informação que S viesse a ganhar. Ele mostra, além disso, que conhecimento que é atacado por contraevidência pode ter seu status

${ }^{12}$ Cf. SORENSEN, R. Dogmatism, junk knowledge, and conditionals. Philosophical Quarterly 38 (153), 1988, p. 438.

\begin{tabular}{|c|c|l|l|c|c|}
\hline Intuitio & $\begin{array}{c}\text { ISSN } \\
1983-4012\end{array}$ & Porto Alegre & Vol.9- $\mathrm{N}^{\mathrm{o} .2}$ & $\begin{array}{c}\text { Dezembro } \\
2016\end{array}$ & pp. 133-149 \\
\hline
\end{tabular}


epistêmico cancelado, e por isso pode não servir como razão para desconsiderar tal contraevidência. No que segue, vamos examinar melhor este princípio ao tratarmos da crítica de Lasonen-Aarnio à solução do paradoxo sugerida por Harman.

\section{Lasonen-Aarnio contra a solução anulabilista}

Contra Harman e aqueles que o seguiram sobre qual seria a correta resolução do paradoxo do dogmatismo, Maria Lasonen-Aarnio sugeriu que a solução anulabilista não resolve o problema pois deixa intacta uma "porção" de dogmatismo ainda autorizada para o sujeito, resultado este que não gostaríamos de conceder.

Lasonen-Aarnio acredita que a única saída para solucionar o paradoxo é negar o assim-chamado "Princípio da Intitulação”, que está trabalhando na premissa (3) do argumento pró-dogmatismo, como vimos anteriormente - a saber, “Se S sabe que E é evidência enganadora contra P, então S está justificado em desconsiderar E.” No entanto, prossegue ela, tal princípio é inicialmente bastante plausível. Sendo assim, deparamo-nos com um dilema: (i) ou condenamos o princípio da intitulação, ou (ii) "aprendemos a viver com o dogmatismo", nas suas palavras ${ }^{13}$.

No que segue, vamos expor e, em seguida, avaliar a crítica de Lasonen-Aarnio à solução anulabilista do paradoxo. Em primeiro lugar, consideraremos em detalhes o que Lasonen-Aarnio crê que são as duas suposições cruciais das quais a conclusão dogmatista depende, a saber, o princípio da estabilidade do conhecimento e o princípio da intitulação. Vamos examiná-los um por vez.

\section{O princípio da estabilidade do conhecimento}

O princípio da estabilidade do conhecimento, como vimos anteriormente, remonta às considerações de Jaakko Hintikka sobre as consequências de saber que uma proposição é o caso. Neste sentido, ele sugeriu que o seguinte é verdadeiro sobre conhecimento proposicional:

Se alguém diz "Eu sei que P" nesse sentido forte de conhecimento, ele implicitamente nega que qualquer outra informação adicional o levaria a mudar a sua opinião. Ele se compromete com a tese de que ele seguiria dizendo que ele sabe que P é verdadeiro . . . mesmo se ele soubesse mais do que ele sabe agora ${ }^{14}$.

${ }^{13}$ LASONEN-AARNIO, M. The dogmatism puzzle. Australasian Journal of Philosophy 94 (3), 2014, 417-432, p.418.

14 "If somebody says "I know that p" in this strong sense of knowledge, he implicitly denies that any further information would have led him to alter his view. He commits himself to the view that he would still persist in saying that he knows that $\mathrm{p}$ is true- or at the very least, persists in saying that $\mathrm{p}$ is, in fact true-even if he knew more than he now knows.” HINTIKKA, J. Knowledge and Belief. Ithaca, N.Y., Cornell University Press, 1962, p. 20-21.

\begin{tabular}{|c|c|l|l|c|c|}
\hline Intuitio & $\begin{array}{c}\text { ISSN } \\
1983-4012\end{array}$ & Porto Alegre & Vol.9- N $^{\circ} .2$ & $\begin{array}{c}\text { Dezembro } \\
2016\end{array}$ & pp. 133-149 \\
\hline
\end{tabular}


A ideia sobre conhecimento que Hintikka expressa acima é tomada por Saul Kripke como sendo equivalente ao seguinte: “ [...] É uma característica do conhecimento que mesmo se eu tiver mais evidência do que eu tenho agora, eu ainda saberei que $\mathrm{P}^{15}$.” O princípio da estabilidade do conhecimento tem sua intuição central capturada pelo slogan "Novo conhecimento não pode prejudicar velho conhecimento ${ }^{16}$."

\section{O princípio da intitulação}

Voltemo-nos, agora, ao princípio da intitulação. Tal princípio parece, à primeira vista, bastante plausível. Afinal, se você sabe que P é o caso, e sabe que E é evidência enganadora contra P, permitir que E tenha qualquer influência sobre o seu sistema doxástico só pode lhe prejudicar, epistemicamente falando, ao lhe afastar da verdade ou lhe roubar alguma porção do seu status epistêmico positivo. Como Lasonen-Aarnio escreveu, "Levar em consideração evidência que se sabe que é enganadora parece como confiar no testemunho de alguém que se sabe que é um mentiroso patológico ${ }^{17}$.”

\section{Qual é o problema com o dogmatista?}

O que é que nos causa perplexidade em relação ao argumento avançado pelo dogmatista? O problema é que a atitude dogmática traz consigo uma carga de arbitrariedade no que concerne o tratamento do conjunto total de evidências. O dogmatista parece violar uma máxima epistêmica da racionalidade, segundo a qual o sujeito deve ajustar as suas crenças às suas evidências (ou melhor, ao seu conjunto total de evidências). Nas palavras de Lasonen-Aarnio, o dogmatista não é "sensível às evidências do modo em que um sujeito epistemicamente racional ou razoável preocupado com a busca da verdade deveria ser ${ }^{18}$.” Desse modo, a recomendação do dogmatismo incita uma política epistêmica de mentefechada, como sugeriu Sorensen ${ }^{19}$.

A solução de Harman ao paradoxo, como vimos acima, concentra-se na negação da premissa (1) do argumento de Lasonen-Aarnio. A dinâmica da revisão de crenças explica por que o sujeito não tem a sua atitude dogmática justificada. Uma vez que ele se depara com contraevidência para o que ele sabe, ele perde o conhecimento atacado e, assim, não é capaz de empregá-lo em um argumento de resistência à ação da contraevidência.

${ }^{15}$ KRIPKE, S. Philosophical Troubles. Collected Papers Vol I. Oxford University Press, 2011, p. 39.

${ }^{16}$ Veja SORENSEN, R. Dogmatism, junk knowledge, and conditionals. Philosophical Quarterly 38 (153), 1988, p.437, para uma breve discussão desse princípio no contexto do paradoxo do dogmatismo.

${ }^{17}$ LASONEN-AARNIO, M. The dogmatism puzzle. Australasian Journal of Philosophy 94 (3), 2014, p. 420.

${ }^{18}$ LASONEN- AARNIO, M. The dogmatism puzzle. Australasian Journal of Philosophy 94 (3), 2014, p. 421.

${ }^{19}$ SORENSEN, R. Dogmatism, junk knowledge, and conditionals. Philosophical Quarterly 38 (153), 1988, p. 434.

\begin{tabular}{|c|c|l|l|c|c|}
\hline Intuitio & $\begin{array}{c}\text { ISSN } \\
1983-4012\end{array}$ & Porto Alegre & Vol.9- $\mathrm{N}^{\circ} .2$ & $\begin{array}{c}\text { Dezembro } \\
2016\end{array}$ & pp. 133-149 \\
\hline
\end{tabular}


Assim, para a solução anulabilista esposada por Harman e alguns seguidores, basta negar o princípio da estabilidade do conhecimento e o problema é resolvido. Não é necessário negar o princípio da intitulação; a hipótese de negar algo como aquele princípio sequer é considerada por Harman.

A crítica de Lasonen-Aarnio concentra-se no seguinte ponto. Se assumirmos essa concepção de derrota epistêmica, não basta negar o princípio da estabilidade do conhecimento para resolver o paradoxo do dogmatismo; um “dogmatismo residual” persistirá a menos que se negue o princípio da intitulação. O problema consiste no fato de que parece ser possível adquirir evidência fraca contra uma proposição P e permanecer sabendo que P e, assim, autorizado a ser dogmático em relação a P. Antes, porém de olharmos para os detalhes da crítica de Lasonen-Aarnio, precisamos dizer algumas palavras sobre derrota epistêmica.

\section{O que é derrota epistêmica?}

Derrota epistêmica é a ação de uma contraevidência (proposicional ou não-proposicional) sobre a justificação epistêmica gozada por uma crença-alvo $P$ de um sujeito $S$, justificação esta advinda do conjunto total de evidências E de S - os justificadores de P. O efeito da ação da contraevidência é a redução ou a destruição completa da justificação que E oferece a P.

Para acomodar o fenômeno da derrota epistêmica, é necessário que façamos algumas suposições. Especificamente, tem-se que admitir o princípio da falibilidade da justificação (boa para conhecimento), isto é, a tese de que o suporte evidencial oferecido a uma crença não precisa ser infalível - tal como a implicação lógica, por exemplo - para que esta crença seja justificada. Uma das consequências desta suposição é que crenças justificadas podem ser falsas.

Admitindo que o critério da justificação não precise ser algo tão exigente como a implicação lógica, supõe-se que há uma espécie de soleira, a qual é necessário cruzar para obter justificação em nível de conhecimento.

Assim, como efeito da derrota epistêmica, a crença em $\mathrm{P}$ de $\mathrm{S}$ pode não mais estar justificada pelas evidências em nível de conhecimento dependendo do ataque que a relação de suporte sofre. Para ilustrar esse ponto, considere o seguinte caso. Imagine que eu vejo o que me parece ser um livro vermelho sobre a mesa. Com base nesta evidência perceptual, eu passo a crer que há um livro vermelho sobre a mesa. Mas, imagine também que eu ganho a informação de que há luzes vermelhas iluminando a mesa sobre a qual o livro está. Eu acabo de ter a minha justificação neutralizada por essa contraevidência. A informação que eu ganhei sobre as luzes vermelhas cancela a justificação que a minha evidência perceptual confere à minha crença de que há um livro vermelho sobre a mesa, pois se o livro fosse branco, por exemplo, ele continuaria parecendo vermelho para mim.

\begin{tabular}{|c|c|l|l|c|c|}
\hline Intuitio & $\begin{array}{c}\text { ISSN } \\
1983-4012\end{array}$ & Porto Alegre & Vol.9- $\mathrm{N}^{\circ} .2$ & $\begin{array}{c}\text { Dezembro } \\
2016\end{array}$ & pp. 133-149 \\
\hline
\end{tabular}


Observe que, dada a suposição de que conhecimento é derrotável e as suas consequências, é possível adquirir evidência fraca contra uma proposição P e ainda assim manter o conhecimento de que P, uma vez que restará justificação em nível de conhecimento. Desse modo, conhecimento nem sempre é derrotado por contraevidência. Há casos nos quais a contraevidência não é forte o suficiente para diminuir o suporte evidencial abaixo da soleira do conhecimento. Lembre-se que a solução anulabilista apela para o fato de que o sujeito perde o conhecimento de P quando este é atacado pela contraevidência e por não ter mais conhecimento, não está mais autorizado a desconsiderá-la. Em situações nas quais a contraevidência é fraca e a justificação ainda "sobrevive” em nível de conhecimento, o sujeito ainda possuiria conhecimento autorizando-o, assim, pelo princípio da intitulação, a desconsiderar a contraevidência. Para ilustrar o ponto, considere o seguinte caso:

Primeiro, um sujeito olha para uma sacola, e passa a saber que há uma bola vermelha e uma bola preta dentro dela, e nada mais. Mas então, após aprender que as primeiras 10,000 tiradas de bola com substituição foram todas vermelhas, ele perde o conhecimento de que havia uma bola preta na sacola (vamos assumir que o sujeito está certo durante todo o tempo que os conteúdos da sacola não mudaram). Deixe h ser a proposição de que há exatamente duas bolas na sacola em to, uma preta e uma vermelha. Agora assumamos que em vez de aprender que as primeiras 10,000 tiradas de bola com substituição foram todas vermelhas, o sujeito adquire evidência aos poucos, como segue: $\mathrm{t}_{1} \mathrm{E}_{1}$ : a bola da tirada 1 foi vermelha; $\mathrm{t}_{2} \mathrm{E}_{2}$ : a bola da tirada 2 foi vermelha; . . .; $\mathrm{t}_{10,000} \mathrm{E}_{10,000}$ : a bola da tirada 10,000 foi vermelha ${ }^{20}$.

Contraevidências para P são adquiridas gradualmente, até que o sujeito não mais cruze a soleira da justificação em nível de conhecimento. Neste determinado tempo, $\mathrm{t}_{\mathrm{i}}, \mathrm{S}$ já não sabe que $\mathrm{P}$ e, então, não mais está autorizado a ser dogmático quanto a P. Porém, se isto é o caso, então haverá um tempo $\mathrm{t}_{\mathrm{n}}$ imediatamente anterior a $\mathrm{t}_{\mathrm{i}}$, tal que neste tempo $\mathrm{S}$ ainda sabe que $\mathrm{P}$ e pode, portanto, ser dogmático quanto a P desconsiderando a contraevidência fraca que recebeu - via princípio da intitulação.

Lasonen-Aarnio chama esta possibilidade de “implausível conclusão dogmatista”, pois o sujeito estaria autorizado a não revisar os seus estados de crença de modo que eles se ajustem ao conjunto total de evidências (que agora inclui a contraevidência recebida). Ele ainda violaria uma exigência razoável sobre racionalidade. Ela explicita esse ponto na seguinte passagem:

Por exemplo, assumamos que em $t_{0}$ um sujeito sabe que $h$, e que a soleira evidencial para o conhecimento encontra-se em algum nível abaixo de 0.95 (os números precisos não importam). Assumamos que em $\mathrm{t}_{0}$ a evidência do sujeito evidencialmente ou racionalmente apoia h em grau 0.99, e que a sua confiança ou grau de crença em h é

20 "First, a subject takes a look into a bag, and comes to know that there is a red and a black ball in it, and nothing else. But then, upon learning that the first 10,000 draws out of the bag with replacement were all red, she loses her knowledge that there was a black ball in the bag (let us assume the subject is certain throughout that the contents of the bag have not changed). Let $\mathrm{h}$ be the proposition that there are exactly two balls in the bag at t0, one black and one red. Now assume that instead of learning that the first 10,000 draws out of a bag with replacement were all red, the subject acquires evidence by bits, as follows: t1E1: Draw 1 was red; t2E2: Draw 2 was red; . . ; t10,000E10,000: Draw 10,000 was red.” LASONEN-AARNIO, M. The dogmatism puzzle. Australasian Journal of Philosophy 94 (3), 2014, p.427.

\begin{tabular}{|c|c|l|l|c|c|}
\hline Intuitio & $\begin{array}{c}\text { ISSN } \\
1983-4012\end{array}$ & Porto Alegre & Vol.9- No.2 & $\begin{array}{c}\text { Dezembro } \\
2016\end{array}$ & pp. 133-149 \\
\hline
\end{tabular}


igualmente 0.99. Se o sujeito adquire alguma evidência contra h, essa relação se dará em um grau menor, mas assumamos que ela ainda se dá em grau 0.96. Enquanto o sujeito continuar sabendo que h, [pelo princípio da] Intitulação ele ainda está justificado em atribuir a h um grau de crença de 0.99 . Mas isso parece profundamente problemático ${ }^{21}$.

A tensão está entre (i) a conclusão dogmatista de que o sujeito está autorizado a não ajustar os seus estados de crença em face de nova evidência incidindo sobre P e (ii) uma máxima da racionalidade epistêmica exigindo que o sujeito leve em conta o seu conjunto total de evidências. O dogmatista admite a discrepância entre o suporte evidencial gozado por P e a atitude doxástica em relação a P. A exigência do ajuste ao conjunto total de evidências é dispensada pelo dogmatista. Uma posição que permite tal discrepância e tal desajuste entre evidências e estados doxásticos é tomada por Lasonen-Aarnio como "simplesmente implausível” 22. Afinal de contas, as crenças ou graus de crença do sujeito "deveriam rastrear o grau em que ele está justificado em crer numa proposição”23.

Lasonen-Aarnio considera a possibilidade de que sua crítica à solução anulabilista do paradoxo mostre simplesmente que não apenas o princípio da estabilidade do conhecimento, mas também o princípio da intitulação deve ser negado. No entanto, acredita ela, esta não é uma possibilidade que merece muita atenção, uma vez que não há razões independentes do paradoxo para negar um princípio tão plausível como o princípio da intitulação ${ }^{24}$. Na intenção de expor tal plausibilidade, ela pede que consideremos a implausibilidade de certas conjunções que decorreriam da negação daquele princípio, tais como: (i) 'E é evidência enganadora contra h, mas eu não deveria desconsiderar E enquanto ela incide sobre h', e (ii) 'E é evidência enganadora contra h, mas eu deveria baixar o meu grau de crença (credence) em h como um resultado de ter adquirido $\mathrm{E}^{25}$, Tais conjunções seriam asseríveis se rejeitássemos o princípio da intitulação. No entanto, como uma asserção se compromete com os dois conjuntos da conjunção, ao asserí-la, o primeiro conjunto faz a atitude de desconsiderar E uma atitude justificada para você, e desse modo você perde o compromisso com o segundo conjunto.

Pode-se concluir, com Lasonen-Aarnio, que embora a solução anulabilista funcione bem enquanto se assume o modelo tradicional de estados de crença, tal solução é insatisfatória ao assumirmos o modelo de graus de crença. Neste último modelo, o pedido pelo ajuste dos estados doxásticos às evidências entra

\footnotetext{
21،"For instance, assume that at time t0 a subject knows h, and that the evidential threshold for knowledge is set at some level below 0.95 (the precise numbers don't matter). Assume that at t0 the subject's evidence evidentially or rationally supports $h$ to degree 0.99 , and that her credence or degree of belief in $h$ is likewise 0.99 . If the subject acquires a bit of evidence against $h$, this relation will hold to a lesser degree, but assume that it still holds to degree 0.96. As long as the subject continues knowing h, by Entitlement she is still justified in assigning to $h$ a credence of 0.99. But this seems deeply problematic." LASONEN-AARNIO, M. The dogmatism puzzle. Australasian Journal of Philosophy 94 (3), 2014, p.427-428.

${ }^{22}$ LASONEN-AARNIO, M. The dogmatism puzzle. Australasian Journal of Philosophy 94 (3), 2014, p.428.

${ }^{23}$ LASONEN-AARNIO, M. The dogmatism puzzle. Australasian Journal of Philosophy 94 (3), 2014, p.429.

${ }^{24}$ Veja VEBER, 2004, para uma solução ao paradoxo do dogmatismo que consiste, justamente, no abandono do princípio de intitulação. Infelizmente, o tratamento da proposta de Veber não cabe no escopo deste ensaio.

${ }^{25}$ LASONEN-AARNIO, M. Unreasonable Knowledge. Philosophical Perspectives 24 (1), 2010, p. 429.
}

\begin{tabular}{|c|c|l|l|c|c|}
\hline Intuitio & $\begin{array}{c}\text { ISSN } \\
1983-4012\end{array}$ & Porto Alegre & Vol.9- N $^{\circ} .2$ & $\begin{array}{c}\text { Dezembro } \\
2016\end{array}$ & pp. 133-149 \\
\hline
\end{tabular}


em conflito com a atitude dogmática autorizada pelo conhecimento que, mesmo derrotado, não foi destruído. ${ }^{26}$

\section{Objeções}

No que segue, vamos considerar três pequenas objeções à crítica de Lasonen-Aarnio à solução anulabilista do paradoxo do dogmatismo.

Como apontamos anteriormente, visto a partir do modelo de crença gradual, o paradoxo do dogmatismo concentra-se na tensão entre (i) a suposta justificação para a tomada de uma atitude dogmática e (ii) a máxima de racionalidade que pede que o sujeito ajuste os seus estados doxásticos às evidências. No entanto, se assumimos a assim-chamada tese Lockeana sobre a conexão entre crenças e graus de crença, tal tensão parece desaparecer. A tese Lockeana sugere que

... é epistemicamente racional, para nós, crer em uma proposição se e somente se é epistemicamente racional, para nós, ter um grau suficientemente alto de confiança nela, suficientemente alto para fazer a nossa atitude em relação a ela um atitude de crença ${ }^{27}$.

Para ilustrar esse ponto, retome o caso das bolas retiradas da bolsa. Em $\mathrm{t}_{3}$, quando eu tiro uma bola da bolsa pela terceira vez, se, como nas duas primeiras vezes, a bola for vermelha, então a minha justificação para crer que há uma bola vermelha e uma bola preta na cesta diminui de, digamos, 0.99 para 0.98. No entanto, parece que, mesmo em face de tal contraevidência, ainda é racional, para mim, ter um

\footnotetext{
${ }^{26}$ Um parecerista anônimo fez a seguinte observação: "Note que o questionamento das credenciais de uma crença pode afetar a crença de que se sabe que $\mathrm{p}$, mas não necessariamente o conhecimento de que p: se é possível separar o conhecimento de uma atitude reflexiva, então é possível avaliar uma aparente contraevidência a p, derrotar a justificação para crer que se sabe que p, sem que com isso se perca o conhecimento de que p.” Do nosso ponto de vista, é implausível pensar que o desafio às credencias epistêmicas de uma crença de que $\mathrm{P}$ não são, necessariamente, desafios ao conhecimento de que P; parece-nos que se as primeiras se perdem, então o último também se perde. Qualquer contraevidência (não-anulada) às credencias epistêmicas de uma crença de que $\mathrm{P}$ acaba com o conhecimento de que $\mathrm{P}$, e não apenas com a meta-crença de que $\mathrm{P}$ - ao menos enquanto se está assumindo justificação epistêmica como condição necessária para o conhecimento. Para as epistemologias não-justificacionistas, há razões para pensar que o problema persistiria, pois tais epistemologias precisam se comprometer, em alguma medida, com uma condição de não-anulabilidade, como Michael Bergmann sugeriu - veja BERGMANN, 1997. Se as credenciais epistêmicas de uma crença de que P são atacadas por uma contraevidência não-anulada, então o sujeito que crê em P não satisfaz a condição de não-anulabilidade e, por consequência, não sabe que P. Uma exceção seria a admissão dos supostos casos de conhecimento irrazoável, apresentados por Lasonen-Aarnio - veja LASONEN-AARNIO, M. Unreasonable Knowledge. Philosophical Perspectives 24 (1), 2010, 1-21.

27 “.... it is epistemically rational for us to believe a proposition just in case it is epistemically rational for us to have a sufficiently high degree of confidence in it, sufficiently high to make our attitude towards it one of belief.” FOLEY, R. The Epistemology of Belief and the Epistemology of Degrees of Belief. American Philosophical Quarterly, 29 (2), 1992, 111-121.
}

\begin{tabular}{|c|c|l|l|c|r|}
\hline Intuitio & $\begin{array}{c}\text { ISSN } \\
1983-4012\end{array}$ & Porto Alegre & Vol.9- No.2 & $\begin{array}{c}\text { Dezembro } \\
2016\end{array}$ & pp. 133-149 \\
\hline
\end{tabular}


grau suficientemente alto de confiança na proposição-alvo - a saber, o grau de 0.98 , que reflete o grau de suporte evidencial considerando a nova evidência. Mas é uma consequência da tese Lockeana que se é racional, para mim, ter um grau suficientemente alto de confiança na proposição-alvo, então é racional, para mim, crer (integralmente) na proposição-alvo. Mas, se é racional, para mim, continuar crendo (integralmente) na proposição-alvo quando a derrota da justificação é mínima como no caso em questão, então eu não sou dogmatista ao desconsiderar a contraevidência. Eu simplesmente continuo racional ao crer na proposição-alvo mesmo após receber a contraevidência; a evidência total me autoriza a seguir crendo. Portanto, (i) nenhum ajuste ou revisão de crenças é necessário sob pena de irracionalidade, e (ii) eu não sou dogmático ao desconsiderar a contraevidência neste caso.

A lição que quero tirar é que quando a minha justificação é derrotada, mas não destruída - de tal modo que continua sendo epistemicamente racional ter um grau suficientemente alto de confiança na proposição-alvo -, nenhum ajuste dos meus estados doxásticos às evidências é exigido sob pena de irracionalidade, de maneira que eu não sou dogmático ao não fazê-lo e seguir crendo a despeito da contraevidência que recebi. Eu estou em conformidade com às evidências, em um sentido importante, sem precisar ajustar nada; estou crendo enquanto é racional, para mim, ter um grau suficientemente alto de confiança na proposição-alvo. Se quando a contraevidência é fraca não há esse dever epistêmico de revisar os estados doxásticos, então não há tensão entre o dogmatismo e algum princípio de racionalidade. Sendo assim, nesses casos, quando a contraevidência é fraca, a solução anulabilista do paradoxo se mantém satisfatória para explicar o fenômeno completamente, e o “dogmatismo residual” de Lasonen-Aarnio desaparece.

\section{II}

A segunda objeção diz respeito à capacidade de S ser sensível às mínimas variações na relação de suporte evidencial que apoia P. Retome, mais uma vez, o caso das bolas retiradas da bolsa. No instante em que a terceira bola é retirada e o sujeito vê que, assim como as duas primeiras, a bola é vermelha, o suporte evidencial para a crença de que há uma bola vermelha e uma bola preta na cesta diminui, digamos, de 0.99 para 0.98. É razoável esperar que S revise os seus graus de crença em face desta nova evidência simplesmente porque ela minimiza um pouco o grau de suporte evidencial? E se ele não o faz, ele é irracional ao manter o seu grau de crença 0.99 (supondo que ele não tem acesso aos números precisos)? Isso não é óbvio. Pelo contrário, não parece ser a nossa atitude num cenário semelhante. Em t8, digamos, $\mathrm{S}$ toma "as primeiras 8 bolas retiradas foram vermelhas" como contraevidência para a crença-alvo, e nota que a relação de suporte não mais autoriza a crença; neste instante ele perde justificação e conhecimento. Mas note que neste caso a explicação anulabilista funciona perfeitamente, diferentemente do caso anterior. Em suma, não parece que em $t_{2}$, ou em $t_{3}$, ou em $t_{4}$, $S$ é irracional ao não revisar os seus estados doxásticos

\begin{tabular}{|c|c|c|c|c|c|}
\hline Intuitio & $\begin{array}{c}\text { ISSN } \\
1983-4012\end{array}$ & Porto Alegre & Vol.9- $\mathrm{N}^{\circ} .2$ & $\begin{array}{c}\text { Dezembro } \\
2016\end{array}$ & pp. 133-149 \\
\hline
\end{tabular}


em face de contraevidência, visto quão mínima é a variação na relação de suporte evidencial, de maneira que o sujeito dificilmente nota qualquer variação.

\section{III}

A terceira objeção desafia a plausibilidade do que assumimos ser constitutivo da atitude de desconsiderar evidência. Lembre-se que assumimos que esta atitude reflete ao menos uma das seguintes alternativas: (i) S não abandona a sua crença em $P$ em vista de E, (ii) S não baixa o seu grau de crença em $\mathrm{P}$ em vista de E. No entanto, ambas as alternativas dizem respeito ao que o sujeito fará depois de refletir sobre o efeito da contraevidência sobre o seu sistema doxástico. Em (i), o sujeito desconsideraria a contraevidência depois de fazer o raciocínio que o dogmatista sugere. Ele conferiria se ainda sabe que P e, se sim, desconsideraria a contraevidência. Em (ii), ele, igualmente, conferiria se ainda sabe que P, mesmo que P tenha sofrido alguma derrota, e, se sim, desconsideraria a contraevidência sem fazer qualquer ajuste. Talvez desconsiderar contraevidência signifique algo anterior ao emprego de qualquer raciocínio pródogmatismo, a saber, não se engajar em um processo de revisão de crenças. Não seria a sugestão do dogmatismo que dispensemos a contraevidência sem sequer refletirmos sobre a sua incidência sobre o status epistêmico de outras crenças? Se esta fosse a real sugestão do dogmatista sobre desconsiderar contraevidência para o que se sabe, este seria um tipo de dogmatismo mais severo, pois absolutamente nada aconteceria depois que o sujeito recebesse a contraevidência; nenhum raciocínio para dispensá-la seria usado; o sujeito simplesmente voltaria a sua atenção para outra coisa. Neste caso, o que mais interessa para a explicação da implausibilidade do dogmatismo não é se o sujeito perde conhecimento, mas sim que as credenciais de $\mathrm{P}$ foram postas em cheque e isto está em tensão com alguma máxima de racionalidade ${ }^{28}$.

\footnotetext{
${ }^{28}$ Um parecerista anônimo fez a seguinte observação: “Assumindo que ação intencional é baseada em conhecimento, note que é possível conceber casos em que a urgência da ação permite desconsiderar algumas evidências. Imagine que um sujeito tem de decidir urgentemente acerca de um curso de ação, digamos, cortar o fio vermelho para desativar uma bomba-relógio. Embora ele saiba que grande maioria das bombas são desativadas se o fio vermelho for cortado, ele dispõe da evidência de que algumas bombas são ativadas caso o fio vermelho seja cortado. Ele então decide ignorar essa evidência porque não cortar nenhum fio também faz com que a bomba exploda. Este não parece ser um caso de "dogmatismo severo" como colocado na terceira objeção, apesar de que o sujeito evita avaliar as suas credenciais. Pelo contrário, o indivíduo parece justificado. Portanto, não parece ser o caso que uma atitude dogmática consiste em ignorar quaisquer contraevidências para crer. ” Parece-nos arriscado assumir que toda ação intencional racional é baseada em conhecimento; parece-nos que muitas instâncias de ação intencional racional são baseadas em crença justificada. E é assim que vemos o caso acima. Na presença de contraevidência não-anulada, o sujeito perde conhecimento, se é que o possuiu alguma vez. Mais importante que isto, é razoável pensar que o sujeito avalia as suas credenciais para a sua crença ainda que tal avaliação epistêmica não supere o valor da tomada de um curso de ação, dado o risco envolvido na situação. Ao misturar a racionalidade da ação com a racionalidade da atitude doxástica do sujeito, o caso passa a ser desinteressante de um ponto de vista puramente epistêmico.
}

\begin{tabular}{|c|c|l|l|c|c|}
\hline Intuitio & $\begin{array}{c}\text { ISSN } \\
1983-4012\end{array}$ & Porto Alegre & Vol.9- No.2 & $\begin{array}{c}\text { Dezembro } \\
2016\end{array}$ & pp. 133-149 \\
\hline
\end{tabular}




\section{Conclusão}

Procuramos ter oferecido ao leitor razões para crer que a solução anulabilista do paradoxo do dogmatismo é adequada para solucionar esse problema, contra a crítica de Lasonen-Aarnio. Ela procurou mostrar que mesmo nos casos em que o sujeito mantém conhecimento da crença-alvo, se ele não ajustar os seus estados doxásticos em resposta à contraevidência, independente da força da contraevidência, então ele está sendo dogmático, e este é um resultado inaceitável.

Nós sugerimos três modos de resistir à conclusão de Lasonen-Aarnio. Em primeiro lugar, apontamos para o fato de que se assumimos a assim-chamada tese Lockeana sobre a relação entre crenças e graus de crença, nos casos em que a derrota epistêmica não causa a destruição do conhecimento, mesmo que o sujeito ajustasse o seu grau de crença na proposição-alvo, ele continuaria justificado em crer nela. Sendo assim, que diferença faria tal ajuste? Por que esse ajuste seria exigido do sujeito sob pena de irracionalidade? Não parece haver qualquer razão. Em segundo lugar, nos casos em questão, a diferença que a contraevidência faz na relação de suporte é tão pequena que o sujeito dificilmente a percebe, e se ele não percebe isto, então ele não a toma como contraevidência. Em terceiro lugar, apontamos para o fato de que o dogmatista poderia estar sugerindo outra coisa ao usar a expressão "desconsiderar evidência” diferente daquilo que Lasonen-Aarnio toma como constituindo tal atitude. Talvez o dogmatista esteja sugerindo que o sujeito, quando sabe que P, está autorizado a não se engajar em qualquer processo de revisão de crenças que afete $\mathrm{P}$.

\section{Referências}

BERGMANN, M. Internalism, externalism and the no-defeater condition. Synthese 110 (3), 1997, 399417.

BORGES, R. On synchronic dogmatism. Synthese 191 (11), 2015, 3677-3693.

FOLEY, R. The Epistemology of Belief and the Epistemology of Degrees of Belief. American Philosophical Quarterly, 29 (2), 1992, 111-121.

HARMAN, G. Thought. Princeton University Press, 1973.

HINTIKKA, J. Knowledge and Belief. Ithaca, N.Y., Cornell University Press, 1962.

KRIPKE, S. Philosophical Troubles. Collected Papers Vol I. Oxford University Press, 2011.

LASONEN-AARNIO, M. Unreasonable Knowledge. Philosophical Perspectives 24 (1), 2010, 1-21.

LASONEN-AARNIO, M. The dogmatism puzzle. Australasian Journal of Philosophy 94 (3), 2014, 417432.

LEHRER, K. Knowledge, Truth and Evidence. Analysis 25 (5), 1965, 168 - 175.

SORENSEN, R. Dogmatism, junk knowledge, and conditionals. Philosophical Quarterly 38 (153), 1988, 433-454.

\begin{tabular}{|c|c|l|l|c|r|}
\hline Intuitio & $\begin{array}{c}\text { ISSN } \\
1983-4012\end{array}$ & Porto Alegre & Vol.9- No.2 & $\begin{array}{c}\text { Dezembro } \\
2016\end{array}$ & pp. 133-149 \\
\hline
\end{tabular}


VEBER, M. What do you do with misleading evidence? Philosophical Quarterly 54 (217), 2004, 557569.

Recebido em: 06 de outubro de 2016.

Aprovado para a publicação em: 22 de novembro de 2016.

\begin{tabular}{|l|c|l|l|c|c|}
\hline Intuitio & $\begin{array}{c}\text { ISSN } \\
1983-4012\end{array}$ & Porto Alegre & Vol.9 $-\mathrm{N}^{\mathrm{o} .2}$ & $\begin{array}{c}\text { Dezembro } \\
2016\end{array}$ & pp. 133-149 \\
\hline
\end{tabular}

